\title{
Saúde e saneamento no Brasil: uma revisão narrativa sobre a associação das condições de saneamento básico com as doenças de veiculação hídrica
}

Title health and sanitation in Brazil: a narrative review on the association of basic sanitation conditions with waterborne diseases

Salud y saneamiento en Brasil: una revisión narrativa sobre la asociación de las condiciones de saneamiento básico con las enfermedades transmitidas por el agua

Recebido: 06/11/2021 | Revisado: 15/11/2021 | Aceito: 23/11/2021 | Publicado: 02/12/2021

\author{
Gabriel Alves Vitor \\ ORCID: https://orcid.org/0000-0002-6083-6593 \\ Universidade de Pernambuco, Brasil \\ E-mail: gabriel.avitor@upe.br \\ Giorge André Lando \\ ORCID: https://orcid.org/0000-0002-4376-265X \\ Universidade de Pernambuco, Brasil \\ E-mail: giorge.lando@upe.br \\ Carolina de Albuquerque Lima Duarte \\ ORCID: https://orcid.org/0000-0001-9086-3739 \\ Universidade de Pernambuco, Brasil \\ E-mail: carolina.albuquerque@upe.br \\ Daniela de Araújo Viana Marques \\ ORCID: https://orcid.org/0000-0002-2380-7910 \\ Universidade de Pernambuco, Brasil \\ E-mail: daniela.viana@upe.br \\ Isabele Bandeira de Moraes D’Angelo \\ ORCID: https://orcid.org/0000-0001-9592-6049 \\ Universidade de Pernambuco, Brasil \\ E-mail: isabele.dangelo@upe.br
}

\begin{abstract}
Resumo
O saneamento básico necessita de uma atenção especial, haja vista a sua relação direta com a saúde humana, preocupação que remonta às mais antigas civilizações. Nesse sentido, a pesquisa tem como objetivo apresentar a relação entre as condições de saneamento básico no Brasil com as doenças de veiculação hídrica. Trata-se de um estudo de revisão narrativa de literatura, com abordagem qualitativa e o método hipotético-dedutivo. Existe uma relação direta entre as doenças de veiculação hídrica e as condições de saneamento básico, principalmente em muitas cidades do interior do país, destacando as regiões Norte e Nordeste do Brasil. De acordo com o IBGE, em 2018, entre as cidades do Brasil, a doença de veiculação hídrica de maior notificação foi a dengue (26,9\% do total), seguida por diarreia $(23,1 \%)$ e verminoses $(17,2 \%)$. Portanto, cabe ao Estado não só a criação de políticas públicas, mas planejamento e investimento no sentido de fazer valer a legislação que regulamenta a prestação de serviços de acesso à água e saneamentos adequados a toda a população.
\end{abstract}

Palavras-chave: Saúde; Saneamento; Direitos; Doenças; Veiculação hídrica.

\begin{abstract}
Basic sanitation needs special attention, given its direct relationship with human health, a concern that dates back to the most ancient civilizations. In this sense, the research aims to present the relationship between basic sanitation conditions in Brazil and waterborne diseases. This is a narrative literature review study, with a qualitative approach and the hypothetical-deductive method. There is a direct relationship between waterborne diseases and basic sanitation conditions, especially in many cities in the interior of the country, especially in the North and Northeast regions of Brazil. According to the IBGE, in 2018, among cities in Brazil, the most notified waterborne disease was dengue $(26.9 \%$ of the total), followed by diarrhea $(23.1 \%)$ and verminosis $(17.2 \%)$. Therefore, it is up to the State not only to create public policies, but also to plan and invest in enforcing the legislation that regulates the provision of adequate access to water and sanitation services to the entire population.
\end{abstract}

Keywords: Health; Sanitation; Rights; Illnesses; Water transmission. 


\begin{abstract}
Resumen
El saneamiento básico necesita una atención especial, dada su relación directa con la salud humana, preocupación que se remonta a las civilizaciones más antiguas. En este sentido, la investigación tiene como objetivo presentar la relación entre las condiciones de saneamiento básico en Brasil y las enfermedades transmitidas por el agua. Se trata de un estudio de revisión de literatura narrativa, con enfoque cualitativo y método hipotético-deductivo. Existe una relación directa entre las enfermedades transmitidas por el agua y las condiciones de saneamiento básico, especialmente en muchas ciudades del interior del país, especialmente en las regiones Norte y Nordeste de Brasil. Según el IBGE, en 2018, entre las ciudades de Brasil, la enfermedad de transmisión hídrica más notificada fue el dengue $(26,9 \%$ del total), seguida de la diarrea $(23,1 \%)$ y la verminosis $(17,2 \%)$. Por lo tanto, le corresponde al Estado no solo crear políticas públicas, sino también planificar e invertir en el cumplimiento de la legislación que regula la provisión de un acceso adecuado a los servicios de agua y saneamiento a toda la población.
\end{abstract}

Palabras clave: Salud; Saneamiento; Derechos; Enfermedades; Enfermedades transmitidas por el agua.

\title{
1. Introdução
}

A importância do saneamento e sua associação à saúde humana remonta às mais antigas culturas. O saneamento desenvolveu-se de acordo com a evolução das diversas civilizações, ora retrocedendo com a queda delas, ora renascendo com o aparecimento de outras. A palavra saneamento é originada do latim “sanu”, que tem sentidos como: tornar são, habitável ou respirável; curar, sarar, sanar; remediar, reparar; e restituir ao estado normal, tranquilizar. De acordo com a Organização Mundial da Saúde (OMS) saneamento é o controle de todos os fatores do meio físico dos seres humanos que exercem ou podem exercer efeitos nocivos sobre o bem-estar físico, mental e social - ou seja, é um conjunto de ações sobre o ambiente que visam a salubridade ambiental na prevenção e controle de doenças, promoção de saúde e qualidade de vida (OMS, 2018). Assim sendo, podemos pressupor que um dos mais importantes fatores determinantes da saúde são as condições ambientais.

Cairncross e Valdmanis (2006) e Scott, Cotton e Govindan (2003) apresentam o saneamento básico como um desafio de saúde pública que tem persistido por décadas, cujas fragilidades em sua estrutura provocam impacto direto no desenvolvimento humano: pobreza crônica, degradação ambiental, aumento da incidência de doenças e morte.

No Brasil, existem inúmeras legislações que visam proporcionar e garantir à população o direito aos serviços básicos que interferem diretamente na sua qualidade de vida. A Lei n ${ }^{\text {8 }}$ 8.080/1990, que regulamenta a operação do Sistema Único de Saúde (SUS), define o saneamento como um dos elementos determinantes e condicionantes dos níveis de saúde da população (Brasil, 1990). No tocante ao saneamento, em 2007 foi promulgada a Lei $n^{\circ} 11.445$ que marcou a regulação da área do saneamento básico no País. A partir desse marco regulatório, definiram-se o conteúdo, as diretrizes para o Plano Nacional de Saneamento Básico (Plansab), que instituiu os princípios como a universalização, ou seja, o acesso aos serviços públicos de abastecimento de água, coleta e tratamento de esgoto, manejo de águas pluviais e manejo de resíduos sólidos, devendo ser ofertado tanto à população urbana quanto rural (Brasil, 2007).

A Lei $n^{\circ} 14.026$ atualizou, em 2020, o marco legal do saneamento básico e alterou a Lei $n^{\circ} 11.445$ para aprimorar as condições estruturais do saneamento básico no País (Brasil, 2020). Apesar de vários esforços, no Brasil, não se observa a universalização de modo efetivo (Carcará et al., 2019). De acordo com Santiago et al. (2020) existe uma disparidade no tocante ao saneamento básico entre as diversas regiões do Brasil, que está relacionada, em parte, pela organização políticoadministrativa em relação aos investimentos, bem como devido à dimensão territorial do país.

Ainda segundo Santiago et al. (2020) apesar do avanço na legislação, a realidade brasileira apresenta ainda disparidades no acesso aos serviços, com a concentração do atendimento nos grandes centros, em detrimento da periferia e do interior. Somam-se também as diferenças regionais, o desequilíbrio entre o número de domicílios que possuem acesso ao abastecimento de água e os que dispõem de rede coletora de esgotos, o perfil de renda dos consumidores e a capacidade de pagamento pelos serviços. 
Conforme Castro et al. (2019) as áreas rurais estão longe da meta de universalização nacional dos serviços de saneamento básico, apresentando indicadores para o abastecimento de água, rede coletora de esgoto e serviço de coleta de resíduos sólidos domiciliares sempre inferiores aos observados nas áreas urbanas.

O Sistema Nacional de Informação sobre o Saneamento (SNIS) é o maior e mais importante ambiente de informações do setor de saneamento básico brasileiro. Este sistema é gerenciado pela Secretaria Nacional de Saneamento do Ministério do Desenvolvimento Regional (SNS/MDR) e reúne informações de caráter operacional, gerencial, financeiro e de qualidade dos serviços de Água e Esgotos (desde 1995), Manejo de Resíduos Sólidos (desde 2002) e Drenagem Pluvial (desde 2015). Indicadores produzidos a partir destas informações são referência para comparação de desempenho da prestação de serviços e para o acompanhamento da evolução do setor de saneamento básico no Brasil (SNIS, 2020).

Os dados de 2019 do SNIS mostram que $92,85 \%$ da população urbana brasileira tem acesso à rede de abastecimento de água, esse número cai para 83,72\% quando o cálculo é feito adicionando a população rural. Além disso, apenas 54,06\% da população (urbana e rural) são atendidos por coleta e tratamento dos seus esgotos gerados e 98,8\% da população têm coleta regular de resíduos sólidos urbanos. Apesar desses números representarem um avanço em relação aos anos anteriores, ainda temos mais de 30 milhões de brasileiros que não possuem água em qualidade e quantidade adequadas para suas necessidades básicas, mais de 100 milhões descartam seus esgotos in natura no ambiente e quase $25 \%$ dos resíduos sólidos gerados são despejados em locais considerados inapropriados, como, por exemplo, aterros controlados e lixões (Brasil, 2020a; Brasil 2020b).

Doenças relacionadas ao sistema veiculação hídrica, por despejo de esgoto inadequado, geram milhões de mortes anualmente em países de baixa renda, com ênfase em regiões de clima quente que experimentam situações tanto de inundações quanto de secas (Neri, 2008). Feachem et al. (1983) ensina que um único grama de fezes de indivíduos infectados pode conter cerca de $10^{6}$ vírus, $10^{8}$ bactérias, $10^{4}$ protozoários e $10^{4}$ ovos de helmintos patogênicos que, caindo em um sistema de saneamento deficiente, podem dar origem a processos de agravos à saúde local. Segundo Mol et al. (2020), arboviroses, como, por exemplo, a dengue, têm como determinantes variáveis socioeconômicas, ambientais e sanitárias. Estes mesmos autores atestam que existem evidências robustas que relacionam a incidência da dengue com a oferta de saneamento, tanto no Brasil como em outros países. Diante disso, a pesquisa tem como objetivo apresentar a relação entre as condições de saneamento básico com as doenças de veiculação hídrica.

\section{Metodologia}

A presente pesquisa se utiliza de um estudo de revisão narrativa de literatura com abordagem qualitativa. De acordo com Rother (2007, p. v) a revisão narrativa é um método que permite "descrever e discutir o desenvolvimento ou o 'estado da arte' de um determinado assunto, sob ponto de vista teórico ou conceitual". Os textos são elaborados a partir da análise da literatura científica e especializada, bem como na interpretação e análise crítica do autor.

Quanto à pesquisa de natureza qualitativa, vale mencionar que nesta o/a pesquisador/a assume um papel importante de interpretação dos dados (Pereira et al., 2018). Assim, para apresentação da proposta teórica foi utilizado o método hipotéticodedutivo. Consequentemente, os dados ora apresentados são majoritariamente qualitativos advindos de fontes secundárias e coletados por um processo indutivo.

Por fim, as reflexões pessoais dos autores foram incorporadas às informações previamente descritas na literatura, para consolidação da proposta apresentada, alcançando o objetivo. Dessa maneira, este artigo é pautado em um processo interdisciplinar com entrelaces das ciências humanas, sociais e da saúde que contribuiu para que os autores pudessem construir a grande linha de raciocínio, ligando os diferentes saberes ao ambiente pandêmico vivenciado pelas populações em situação de vulnerabilidade. 


\section{Componentes do Saneamento Básico}

\subsection{Manejo de resíduos sólidos}

Resíduos sólidos, segundo a Política Nacional de Resíduos Sólidos (Lei 12.305/2010), são definidos como sendo todo material, substância, objeto ou bem descartado resultante de atividades humanas em sociedade. Estes podem se encontrar nos estados sólido ou semissólido, bem como gases contidos em recipientes e líquidos cujas particularidades tornem inviável o seu lançamento na rede pública de esgotos ou em corpos d'água (Brasil, 2020).

De acordo com Silva et al. (2020) nos últimos anos ocorreu um grande aumento nos índices de geração de resíduos sólidos urbanos devido, principalmente, à ascensão da renda da população e ao aumento de produção e consumo vigentes. Esse aumento substancial torna-se um entrave para os gestores municipais no tocante a oferta dos serviços de coleta, transporte e disposição final desses materiais. A baixa efetividade desse serviço acarreta danos visuais à cidade, agravando o problema de poluição ambiental, bem como compromete a qualidade de vida e a saúde dos moradores.

Entre as doenças relacionadas ao saneamento inadequado também estão incluídas aquelas associadas com os resíduos sólidos. Os locais em que ocorre a disposição inadequada desses resíduos atraem animais sinantrópicos, além de poluir as águas superficiais e subterrâneas, o solo e o ar. A conservação da limpeza dos ambientes evita, portanto, acúmulo de resíduos e, consequentemente, os impactos negativos sobre as condições sanitárias vigentes (Landau; Moura, 2016).

A décima oitava edição do Diagnóstico do Manejo de Resíduos Sólidos Urbanos (ano referência 2019) elaborou um diagnóstico com base nas informações fornecidas pelos municípios sobre a cobertura do serviço regular de coleta de resíduos domiciliares, as informações sobre a massa coletada, a coleta seletiva, entre outras (Brasil, 2020b). Um dos dados alarmantes contabilizados nesta $10^{\mathrm{a}}$ edição foi o despejo de 15,9 milhões de toneladas de resíduos em unidades de disposição final consideradas inadequadas (aterros controlados e lixões), que correspondem juntas a 24,9\% do total disposto em solo em 2019. A região nordeste obteve o pior desempenho entre as macrorregiões do país tanto em relação a sua participação para a coleta dos dados $(47,9 \%)$ quanto em relação ao índice de cobertura de serviços de coleta de resíduos sólidos domiciliar (97,7\%) (Brasil, 2020b).

\subsection{Esgotamento sanitário e Abastecimento de água}

Em 2019 foi publicada a vigésima quinta edição do Diagnóstico dos Serviços de Água e Esgotos do SNIS que foi elaborado com base nas informações fornecidas por companhias estaduais, empresas e autarquias municipais, empresas privadas e, em muitos casos, pelas próprias prefeituras, todos denominados no SNIS como prestadores de serviços. Os dados do SNIS, com relação a abastecimento de água, apontam que $98,15 \%$ da população urbana brasileira reside em municípios que possuem sistema público, enquanto apenas $0,03 \%$ residem em municípios que possuem somente soluções alternativas individuais ou coletivas de água (poço ou nascente, chafariz, carro-pipa, dentre outras). Além disso, ressalta-se que outros $1,82 \%$ residem em municípios que não responderam ao SNIS em 2019. Os consumos variam regionalmente de 120,6 1/hab/dia no Nordeste (menor índice) a 177,4 1/hab/dia no Sudeste (maior índice) (Brasil, 2020a).

Com relação ao esgotamento sanitário, 85,58\% da população urbana brasileira reside em municípios que possuem sistema público de esgotos, enquanto $7,40 \%$ residem em municípios que não possuem sistema público e utilizam sistemas alternativos (fossa séptica, fossa rudimentar, vala a céu aberto, lançamento em cursos d’água, dentre outras). Ressalta-se, ainda, que outros 7,02\% residem em municípios que não responderam ao SNIS no ano de 2019. De acordo com os dados obtidos o SNIS aponta que o esgotamento sanitário ainda tem muito a evoluir quando comparada com o abastecimento de água. Ao se fazer uma análise dos resultados segundo macrorregião geográfica do Brasil, observa-se que, em 2019, a macrorregião Nordeste apresentou o menor valor (9,0 m/ligação) de extensão da rede de esgoto por ligação (Brasil, 2020a).

Inúmeros agravos a saúde e mortes são ocasionados por exposição a ambientes insalubres e saneamento deficiente, 
dentre estes agravos à saúde podem ser incluídas as doenças transmitidas por veiculação hídrica (Silva et al., 2017). Segundo Razzolini e Günther (2008) o processo epidemiológico de doenças transmissíveis envolve uma série de processos complexos, com várias determinantes sociais e econômicas. Na grande maioria das ocorrências, alterações de recursos hídricos causadas por problemas de saneamento e por poluição têm papel relevante na evolução dessas enfermidades. Rodrigues e Malafaia (2009) e Moraes e Jordão (2002) mostraram como a degradação dos recursos hídricos impacta a saúde pública, em função da transmissão de doenças pela água, pela falta de limpeza ou higienização pela água ou por vetores que se relacionam com a água.

\section{Relação entre as Condições de Saneamento Básico e a Incidência de Doenças de Veiculação Hídrica}

Nos últimos tempos, devido à expansão territorial das cidades, à alta densidade populacional e às carências habitacionais, como as invasões, especialmente em áreas rurais, associado à baixa capacidade de desenvolvimento da infraestrutura socioambiental, contatou-se uma maior inadequação dos sistemas de coleta de esgoto e de resíduos sólidos, prejudicando o ambiente e, consequentemente, o controle das doenças relacionadas à essa degradação das águas. O direito à água potável é essencial para fins domésticos habituais, incluindo a higiene pessoal; segundo a Organização Mundial da Saúde, cerca de 8 em cada 10 pessoas que vivem em áreas, principalmente rurais, em todo o mundo, não têm acesso a serviços básicos de água potável, assim como 7 em cada 10 não têm disponibilidade aos serviços de saneamento básico (OMS, 2020a; Ataide; Borja, 2017; Vila Nova; Tenório, 2019). Diante disso, quando há um desequilíbrio na concentração desses agentes patogênicos no ambiente, ocorrem os surtos e as epidemias, aumentando consideravelmente a transmissão de doenças de veiculação hídrica (OMS, 2020b).

Em termos gerais, as doenças de veiculação hídrica são transmitidas por via fecal-oral, ou seja, pela ingestão de água contaminada com fezes de origem animal ou humana infectadas com patógenos (bactérias, vírus, fungos, protozoários e helmintos). Amebíase, ascaridíase, cólera, giardíase e hepatite A são exemplos de doenças relacionadas com a ingestão de água contaminada e que apresentam sintomas semelhantes como: febre, dores abdominais, diarreia com sangue, flatulência, anemia e, até mesmo, morte. Outra, como a esquistossomose, é transmitida após a penetração de larvas (cercárias) pela nossa pele e mucosas quando a pessoa entra em contato com água doce contaminada. Na fase aguda, pode desencadear emagrecimento, dores de cabeça, náuseas e vômitos, diarreia, febre. Na fase crônica, o fígado e o baço podem estar aumentados. Águas contaminadas com urina de rato podem conter uma bactéria espiroqueta e Gram-negativa, a Leptospira interrogans, agente etiológico da leptospirose. Além desses, existem os vetores, como o mosquito Aedes aegypti, que se desenvolvem em ambientes aquáticos, e transmitem doenças como as arboviroses: zika, chikungunya e a dengue (Vila Nova; Tenório, 2019; São Paulo, 2009).

O controle e notificação compulsória das doenças de transmissão hídrica são realizados pelo Sistema de Informação de Agravos de Notificação-Sinan da Vigilância Epidemiológica, Ministério da saúde. Dentre essas enfermidades, destaca-se a doença diarreica aguda (DDA), que é uma síndrome causada por diferentes agentes etiológicos (bactérias, vírus e parasitos), cujas manifestações estão no aumento do número de evacuações, com fezes aquosas ou de pouca consistência, febre e dor abdominal. Os agentes mais frequentes são de origem bacteriana e virais, isolados ou associados, como por exemplo, Salmonella spp., Rotavírus, Norovírus e Adenovírus (Portaria no 205 de 17 de fevereiro de 2016). Ressaltando que outros quadros também podem ocorrer, como manifestações respiratórias, neurológicas, alterações hepáticas, oculares, de pele e do sistema linfático, entre outros, todos relacionados ao tipo do agente etiológico causador, grau de patogenicidade, susceptibilidade do indivíduo, do tempo decorrido entre o início dos sinais e sintomas e o tratamento (MS, 2018). 
Devido à degradação dos recursos hídricos e o consumo de água inadequada, houve um aumento considerável da morbidade/mortalidade por essas doenças (Vila Nova; Tenório, 2019). Em todo o mundo, em 2016, 1,9 milhões de mortes foram atribuídas à falta de higiene. Dentre essas, $13 \%$ se referem a crianças entre 0-5 anos e a maior parte por diarreia (OMS, 2019). De acordo com a Organização Mundial de Saúde, em 2017, 3 bilhões de pessoas não tinham instalações básicas para higienização frequente e adequada das mãos em casa, um ato simples que é uma das medidas mais importantes que podem ser usadas para prevenir a infecção com o vírus SARS-CoV-2, agente da COVID-19 (OMS, 2020c).

Sabe-se que existe uma relação direta entre as doenças de veiculação hídrica e as condições de saneamento básico, principalmente em muitas cidades do interior do país, destacando as regiões Norte e Nordeste do Brasil. Segundo o IBGE, em 2018, entre as cidades do Brasil, a doença de veiculação hídrica de maior notificação foi a dengue (26,9\% do total), seguida por diarreia $(23,1 \%)$ e verminoses $(17,2 \%)$. Segundo o Ministério da Saúde, em Pernambuco, entre 2008 e 2014, a taxa de internação por Doença Diarreica Aguda em crianças menores de 1 ano foi de 232,3 e 71,9/10.000 habitantes, respectivamente. Para a faixa etária entre 1-4 anos, a variação foi de 115,1-43,62/10.000 (DATASUS, 2016), ressaltando que aqueles menores de 4 anos são mais suscetíveis à ocorrência deste agravo. Essa redução na taxa de internações entre 2008 e 2014, e consequentemente da mortalidade, se deve, possivelmente, à melhoria na assistência e resolução da atenção básica, bem como nota-se que houve um crescimento na cobertura do saneamento em diversas áreas do estado (Batista, 2016; Dias, 2010).

Em 2020, além dessas enfermidades citadas, surgiu, no Brasil, os primeiros casos de infecção pelo vírus SARS-CoV2, o qual também pode ser transmitido pela água contaminada por esgotos de indivíduos doentes e que não são tratadas. Apesar de ser baixo o risco de transmissão do vírus que causa a COVID-19 por meio de sistemas de esgoto, quando existe coleta e tratamento (com desinfecção), é importante ressaltar que a etapa de desinfecção de esgotos não é obrigatória e, dessa forma, não é praticada no Brasil (Instituto Trata Brasil, 2020).

Nesse sentido, são necessários esforços especiais para controlar essas doenças transmitidas pela água, principalmente nas comunidades mais vulneráveis das pequenas cidades (Vila Nova; Tenório, 2019). Segundo o Instituto Trata Brasil, cada R\$ 1 investido em Saneamento gera uma economia de R \$ 4 com gastos na área da saúde no Brasil, diante disso é necessário o enquadramento legal das águas, introduzido por meio da Lei $\mathrm{n}^{\circ}$ 14.026/2020, que descreve as seguintes metas: $99 \%$ da população com água potável em casa e 90\% da população com coleta e tratamento de esgoto até dezembro de 2033 (Diário Oficial Da União, 2020).

\section{Indicadores Relacionados à Água para Consumo Humano e Doenças de Veiculação Hídrica}

Conforme abordado na seção anterior, a degradação dos recursos hídricos causa diversos danos para a saúde da população, e que vai além dos problemas provocados pela ingestão de água inadequada. Segundo Instituto Trata Brasil existem desigualdades regionais na distribuição de água em todo país e entre as áreas urbanas e rurais. No ranking de Saneamento referente ao ano de 2019, dos 20 piores municípios, 7 se encontram na região Norte, 4 na região Nordeste, 4 são do Rio de Janeiro, 3 do Rio Grande do Sul, 1 na região Centro-Oeste e 1 na região Sudeste. Logo, caso as normas de controle e vigilância da qualidade de águas estabelecidas pela Resolução n. 357/2005, do Conselho Nacional de Meio Ambiente e pela Portaria MS n..$^{\circ} 2.914$ de 2011, não sejam cumpridas, as consequências podem gerar impactos nos serviços de saúde como surtos e epidemias; impactos econômicos, pela impossibilidade de os trabalhadores doentes exercerem as suas atividades, entre outros impactos negativos (Brasil, 2005; Brasil, 2012; Lima-Camara, 2016). Isso significa que o número de óbitos por doenças de veiculação hídrica não está apenas relacionado com as questões de saneamento básico, mas, sobretudo, com a cobertura da atenção básica, com o percentual de domicílios sem rede elétrica, com moradores de baixa renda e com altos índices de analfabetismo (Batista, 2016). 
Os estados da região Nordeste são os mais acometidos pela falta de organização e fiscalização na coleta e tratamento de água. Nas Pesquisas disponíveis no IBGE no ano de 2017, em Pernambuco, apenas 51 cidades (34,2\%) possuem estações de tratamento de esgoto, o quarto pior do país, atrás apenas de Sergipe (33,3\%), Amazonas (25,0\%) e Amapá (16,7\%). Adicionalmente, $19 \%$ das cidades pernambucanas não tem rede coletora de esgoto; 50,9\% da água tratada é mal distribuída e se perde no caminho até a casa do consumidor; e o estado tem o maior percentual de captação de água salobra do país, 23\%, mais que todo o Nordeste $(10,2 \%)$ e muito acima da média nacional (2,7\%). No interior de Pernambuco, em zonas rurais, a situação é ainda mais alarmante, 56 municípios não possuem rede de distribuição de água e outros 111 não contavam com sistema de coleta de esgoto para essas áreas (IBGE, 2018; IBGE, 2017).

De acordo com a vigilância de saúde, a qualidade da água para consumo humano e uso para higienização seguem os seguintes indicadores para análise da água: indicador sanitário da eficiência da filtração durante o processo de tratamento: turbidez; os bioindicadores de contaminação: coliformes totais e Escherichia coli; indicador de potabilidade microbiológica por meio da inativação de organismos patogênicos: cloro residual livre. A presença de bactérias do grupo dos coliformes totais representa contaminação por material fecal humano e/ou animal, e serve como indicador sanitário de integridade do sistema de distribuição de água tratada para consumo humano. Caso se confirme a existência de E. coli e coliformes termotolerantes em águas tratadas vale checar se há alguma falha na ação do agente desinfetante (no caso o cloro ou outro tão eficiente quanto) ou infiltrações que podem permitir o acúmulo de sedimentos e matéria orgânica, promovendo o desenvolvimento de bactérias (OMS, 2017a; OMS, 2017b).

Partículas em suspensão indicam turbidez que é outro indicador importante a se considerar, já que indica a presença de outros microrganismos patogênicos, como protozoários, incluindo oocistos de Cryptosporidium spp. e cistos de Giardia spp., conferindo grande importância sanitária na qualidade e controle da água (OMS, 2017a).

Segundo a Diretriz Nacional do Plano de Amostragem da Vigilância da Qualidade da água para Consumo Humano, o percentual de amostras fora do padrão de potabilidade, por parâmetro selecionado, segundo a forma de abastecimento de água está associado com as morbimortalidades por doenças de veiculação hídrica. Essa é a realidade representada pela qualidade da água consumida pela população das regiões Norte e Nordeste do Brasil que apresentam conformidade inferior para os indicadores de potabilidade comparada àquela observada nas regiões Sudeste e Sul, provando que existe desigualdade na qualidade da água tratada e distribuída para a população das regiões brasileiras. Diante disso, cabe as autoridades municipais e/ou estaduais junto aos órgãos responsáveis de controle e vigilância diagnosticar a situação do abastecimento de água, avaliar e gerenciar os riscos à saúde a partir das informações geradas e avaliar o cumprimento da norma de potabilidade vigente (MS, 2016).

Ao analisar um desses instrumentos, é fundamental o enquadramento legal das águas, com tratamento básico das águas e/ou efluentes, estudos técnicos que viabilizem o funcionamento de galerias pluviais e efetiva participação popular na gestão das cidades e melhoria das políticas públicas. Portanto, uma melhor compreensão sobre os processos de planejamento e elaboração de planos, visando identificar matrizes que conduzam a programas transformadores da realidade socioambiental, sendo um importante desafio para avançar com a valorização de políticas públicas que colaborem com a promoção da saúde coletiva de forma descentralizada, o que possibilita a apropriação de informações pela população mais vulnerável. Planejamento de áreas urbana e rural voltado para o tratamento de resíduos sólidos e gerenciamento de águas pluviais, de forma a evitar grandes sistemas de escala, como aterros em áreas distantes da cidade, e a construção de sistemas de gestão de água, como bacias de retenção, por exemplo. Na linha curativa, promover saúde através do processo educativo por meio da disseminação do conhecimento sobre transmissão/ doença/ saúde e consequentemente reduzir a morbimortalidade por agravos e doenças de transmissão hídrica (Brasil, 2015; Brasil, 2016). 
Segundo o estudo do Ranking de Saneamento nos municípios brasileiros no ano de 2019, as 20 cidades com estrutura de saneamento inferior tiveram um investimento anual mediano por habitante no período de 2015 a 2019 de $\mathrm{R} \$ 31,45$, ou seja, $72 \%$ abaixo do patamar nacional médio para a universalização (R\$ 113,30). Como essas cidades possuem indicadores muito atrasados e distantes da universalização, a necessidade de aumentar seu patamar de investimentos é substancialmente maior (Instituto Trata Brasil, 2021).

Diante dessa realidade, em muitos países em desenvolvimento, os atuais objetivos de cobertura nacional têm base na obtenção de acesso a infraestruturas básicas, que nem sempre podem fornecer serviços continuamente seguros e confiáveis. Os investimentos planejados ainda não levaram em conta as metas dos Objetivos de Desenvolvimento Sustentável relacionadas à água e ao saneamento, muito mais ambiciosas, que visam o acesso universal a serviços de água e saneamento seguros para 2030 (WHO, 2017). Em Pernambuco, segundo a Companhia Pernambucana de Saneamento - COMPESA, através de projetos e investimentos, aposta na meta de 90\% dos municípios com cobertura e tratamento das águas até 2037 (IBGE, 2017).

\section{O Abastecimento de Água Potável e o Saneamento Básico como Direitos Fundamentais}

Os direitos humanos são direitos universais, indivisíveis, e relacionam-se entre si, devendo ser norteados pelos princípios da igualdade e equidade, os quais respaldam o direito humano fundamental à água potável, como direito essencial a vida. Deve ser considerado especialmente importante para os direitos humanos o acesso a água e ao saneamento básico, que tem diversos desafios de implementação destes como direito fundamental (Maia, 2017).

A Constituição Federal de 1988 (CF/88), em seu art. 225, caput, instituiu que "todos têm direito ao meio ambiente ecologicamente equilibrado, bem de uso comum do povo e essencial à sadia qualidade de vida, impondo-se ao poder público e à coletividade o dever de defendê-lo e preservá-lo para as presentes e futuras gerações” (Brasil, 1988).

No tocante ao direito ao uso da água de qualidade a Constituição da República Federativa do Brasil prevê o acesso à água apenas como uma política pública nacional, ademais, outorga em seu artigo 21, inciso XIX, que a União tem competência para instituir sistema nacional de gerenciamento de recursos hídricos e definir critérios de outorga do direito de uso, o qual fora regulamentado pela Lei no 9.433/1997 e que instituiu a Política Nacional de Recursos Hídricos (PNRH) (Brasil, 1988; Brasil, 1997).

Nesta senda, o dispositivo constitucional do art. 23, IX, caminha no sentido de que é de competência comum da União, Estados, Distrito Federal e dos Municípios promover programas de saneamento básico, como o abastecimento de água, esgotamento sanitário, limpeza urbana e manejo dos resíduos sólidos, realizados de forma adequada à saúde pública, à conservação dos recursos naturais e à proteção do meio ambiente (Brasil, 1988).

Nesse contexto, o direito a água potável e ao saneamento foi explicitamente reconhecido pela Organização das Nações Unidades (ONU) como um direito humano, essencial para o pleno desfrute da vida na declaração "ONU Água" para o Dia Mundial da Água de 2010 (WHO, 2010).

Em consonância, o Ministério da Saúde, através da Portaria nº 2.914/2011, considera potável a água utilizada para consumo humano e cujos parâmetros microbiológicos, físicos e químicos atendam ao padrão de potabilidade e que não ofereça riscos à saúde (Brasil, 2011).

A partir desse reconhecimento em 2010, pela Assembleia Geral das Nações Unidas, o direito à água potável de qualidade e a instalações sanitárias tornou-se um direito, indispensável para o pleno gozo do direito à vida, o que determina que todos têm direito à água e a serviços de saneamento, financeiramente acessíveis, sem qualquer tipo de discriminação, obrigando Estados, progressivamente, a eliminarem as desigualdades de acesso, tanto à água como aos serviços de coleta e tratamento de esgoto (Brito, 2020). 
No âmbito do Estado de Pernambuco, foi criada em 29 de julho de 1971 a Companhia Pernambucana de Saneamento (COMPESA), que tem por atribuição a execução da política governamental de abastecimento de água e esgotamento sanitário, e bem assim a preservação e aproveitamento dos recursos hídricos no Estado de Pernambuco, Art. 1 da Lei Estadual n. 6.307/71 (Brasil, 1971).

Em que pese, no Brasil a Lei ${ }^{\circ}$ 11.445/07 "foi concebida de forma a abrigar todas as formas legalmente possíveis de organização institucional dos serviços de saneamento básico, coerente com as múltiplas realidades sociais, ambientais e econômicas do Brasil.” (Pereira JR. p.7).

Assim, com base nos ditames constitucionais e infraconstitucionais acima expostos, a lei 11.445/07 estabelece diretrizes para as políticas da União e dos demais entes da federação referentemente ao tema do saneamento básico (Brasil, 2020). Por sua vez, a Lei Federal supracitada, que regula as diretrizes do saneamento básico no país foi alterada pela Lei que ficou conhecida como "Novo Marco Regulatório do Saneamento Básico", Lei no 14.026/20, sancionada em 15 de julho de 2020, prevendo o fornecimento de água potável para 99\% da população e coleta e tratamento de esgoto para $90 \%$ até 2033 (Brasil, 2020).

Este novo marco regulatório do saneamento básico, passou a estimular a concorrência, a privatização de empresas públicas estatais de saneamento, entre outras inovações para enfrentar de forma mais célere os graves problemas ambientais e de saúde pública causados pela precarização do saneamento no Brasil (Antunes; Oliveira, 2020).

Dentre as diretrizes elencadas pela nova legislação, o art. $2^{\circ}$ busca a universalização do acesso à população, a efetivação na prestação dos serviços regionalizadas, a governança e transparência dos prestadores dos serviços por meio de licitação (art. 10 da Lei $\mathrm{n}^{\circ}$ 11.445/07), proteção à saúde e políticas públicas. Assim, o Novo Marco Legal concedeu competência à Agência Nacional de Águas (ANA), Autarquia Federal, para instituir as normas de referência para regulação dos serviços públicos de saneamento básico, conforme dispõe o artigo $1^{\circ}$ da legislação. O Portal da ANA (2020) aponta que dentre os principais pontos do Novo Marco Legal, estão os blocos de municípios que irão fornecer atendimento aos pequenos municípios do interior, garantindo acesso à prestação dos serviços, que é o déficit atual (Brasil, 2007; Brasil, 2020; Gadelha, 2021).

Também relevante mencionar que, em 2015, os países tiveram a oportunidade, por intermédio da ONU, de chegar a um acordo global acerca do desenvolvimento sustentável, intitulado Agenda 2030 para o Desenvolvimento Sustentável o qual resultou em uma lista com 17 (dezessete) objetivos a serem alcançados até 2030 e um deles, especificamente o objetivo de número 6, destaca a necessidade de uma gestão sustentável da água e do acesso ao saneamento (ONU, 2017).

Sendo assim, cabe ao poder público, de forma direta ou indireta, sanar a desigualdade do acesso e distribuição do serviço de abastecimento de água potável e de saneamento básico no país, fazendo valer a garantia de direito humano fundamental elencada pelas normas legais brasileiras e dos tratados internacionais, estendendo a todos os cidadãos o direito de usufruir de um bem público universal e essencial à vida (Felippe, 2020).

\section{Considerações Finais}

De forma geral, a ocupação urbana desordenada, a precariedade da limpeza pública, o acúmulo de resíduos sólidos urbanos, os sistemas públicos falhos de abastecimento de água e esgotamento sanitário e a insuficiência dos sistemas de drenagem estão intrinsecamente relacionados ao adoecimento da população brasileira (Corrêa; Palhares, 2016) e configuram-se em sérios problemas de saúde pública por meio de patologias infectocontagiosas, criando um cenário negativo para o controle de surtos e epidemias (Neri, 2008).

Contudo, as enfermidades ora apontadas não se limitam aos espaços urbanos. A população rural também é bastante afetada. Embora no campo o número de habitantes seja inferior, observa-se que o acesso aos serviços públicos de 
abastecimento de água, coleta e tratamento de esgoto, manejo de águas pluviais e manejo de resíduos sólidos, ali ofertados são significativamente reduzidos quando comparado com a zona urbana, e como consequência, em razão da relação direta entre as doenças de veiculação hídrica e as condições de saneamento básico, tanto a população urbana quanto a rural sofrem das referidas mazelas.

Vale lembrar que, o acesso à água foi reconhecido como direito fundamental, ainda que tardiamente, na data de 28 de julho de 2010, pela Assembleia Geral das Nações Unidas, através da Resolução A/RES/64/292, que declarou água limpa e segura, bem como, o saneamento, direitos humanos essenciais para a vida e todos os outros direitos humanos. Portanto, cabe ao Estado o dever de garantir a oferta adequada de água de boa qualidade de forma igualitária para toda a população. Entretanto, não é o que se verifica no Brasil, mesmo com a publicação do Decreto n. ${ }^{\circ} 7.535 / 2011$, que institui o Programa Nacional de Universalização do Acesso e Uso da Água, as regiões consideradas mais vulneráveis do país, a exemplo das regiões Norte e Nordeste, continuam desprovidas desses serviços, por conseguinte, são aquelas que apresentam os piores índices de enfermidades e mortalidades decorrentes de doenças de veiculação hídricas.

No entanto, oportuno registrar uma vez mais, que o número de enfermidades e óbitos por doenças de veiculação hídrica perpassa outras questões além do saneamento básico, como a carência de cobertura da atenção básica, de domicílios sem rede elétrica, o expressivo número de moradores de baixa renda e com altos índices de analfabetismo. Logo, a criação de políticas públicas e investimentos para resolver os problemas relacionados com a água e o saneamento básico são bem-vindos, mas não podem vir sozinhos, pois, faz-se necessária que as políticas sejam compatíveis com outras políticas afins, com ações bem coordenadas entre os atores que participam de sua formulação e implementação. Desse modo, seria possível assegurar retornos sociais elevados.

\section{Referências}

Ataide, G.V.T.L. \& Borja, P.C. (2017). Social And Environmental Justice In Basic Sanitation: A View On Municipal Planning Experiences. Ambiente \& Sociedade, São Paulo, v. XX, n. 3, p. 61-78, jul.-set.

Antunes, P. B., \& D Oliveira, R. D. (2020). Breves considerações sobre o novo marco regulatório do saneamento básico - Lei n 14.026 , de 15 de julho de 2020. http://genjuridico.com.br/2020/07/23/marco-regulatorio-saneamento-basico/. Acesso em: 20/10/2021.

Batista, C.S. (2016). Doenças diarreicas agudas relacionadas ao saneamento básico no Estado de Pernambuco no período de 2008 a 2014.2016 .63 f. Dissertação (Mestrado em Gestão e Economia da Saúde) - Universidade Federal de Pernambuco, Recife.

Brasil. (2010). Lei n 12.305 de 02 de agosto de 2010. Institui a Política Nacional de Resíduos Sólidos; altera a Lei nº 9.605 , de 12 de fevereiro de 1998; e dá outras providências. DF: Presidência da República. Disponível em: http://www.planalto.gov.br/ccivil_03/_ato2007-2010/2010/lei/112305.htm Acesso em: 20/02/2019.

Brasil. (2005). Conselho Nacional de Meio Ambiente. Dispõe sobre a classificação dos corpos de água e diretrizes ambientais para o seu enquadramento, bem como estabelece as condições e padrões de lançamento de efluentes, e dá outras providências. Resolução CONAMA n. ${ }^{\circ} 357$, de 17 de março de 2005. Disponível em: http://pnqa.ana.gov.br/Publicacao/RESOLUCAO_CONAMA_n_357.pdf Acesso em: 20/02/2021.

Brasil. (2007). Lei $\mathrm{n}^{\circ} 11.445$ de 05 de janeiro de 2007. Estabelece as diretrizes nacionais para o saneamento básico; cria o Comitê Interministerial de Saneamento Básico; altera as Leis ${ }^{\text {os }}$ 6.766, de 19 de dezembro de 1979, 8.666, de 21 de junho de 1993, e 8.987, de 13 de fevereiro de 1995; e revoga a Lei ${ }^{\circ}$ 6.528, de 11 de maio de 1978. DF: Presidência da República. Disponível em: http://www.planalto.gov.br/ccivil_03/_ato2007-2010/2007/lei/l11445.htm Acesso em: 20/02/2021.

Brasil. (2020). Lei $\mathrm{n}^{\circ}$ 14.026, de 15 de julho de 2020. Atualiza o marco legal do saneamento básico e altera a Lei $\mathrm{n}^{\circ} 9.984$, de 17 de julho de 2000 , para atribuir à Agência Nacional de Águas e Saneamento Básico (ANA) competência para editar normas de referência sobre o serviço de saneamento, a Lei no 10.768 , de 19 de novembro de 2003, para alterar o nome e as atribuições do cargo de Especialista em Recursos Hídricos, a Lei no 11.107, de 6 de abril de 2005, para vedar a prestação por contrato de programa dos serviços públicos de que trata o art. 175 da Constituição Federal, a Lei no 11.445 , de 5 de janeiro de 2007, para aprimorar as condições estruturais do saneamento básico no País, a Lei $n^{\circ} 12.305$, de 2 de agosto de 2010, para tratar dos prazos para a disposição final ambientalmente adequada dos rejeitos, a Lei $\mathrm{n}^{\circ} 13.089$, de 12 de janeiro de 2015 (Estatuto da Metrópole), para estender seu âmbito de aplicação às microrregiões, e a Lei $\mathrm{n}^{\circ} 13.529$, de 4 de dezembro de 2017, para autorizar a União a participar de fundo com a finalidade exclusiva de financiar serviços técnicos especializados. DF: Presidência da República. Disponível em: http://www.planalto.gov.br/ccivil_03/_ato2019-2022/2020/lei/114026.htm Acesso em: $20 / 02 / 2021$.

Brasil. (1990). Lei no 8.080 de 19 de setembro de 1990. Dispõe sobre as condições para a promoção, proteção e recuperação da saúde, a organização e o funcionamento dos serviços correspondentes e dá outras providências. Brasília, DF: Presidência da República, [1990]. Disponível em: http://www.planalto.gov.br/ccivil_03/leis/18080.htm Acesso em: 20/02/2021. 
Brasil. (2011). Ministério da Saúde. Portaria n ${ }^{\circ}$ 2.914, de 12 de dezembro de 2011. Dispõe sobre os procedimentos de controle e de vigilância da qualidade da água para consumo humano e seu padrão de potabilidade. Diário Oficial [da] República Federativa do Brasil, Brasília, DF, 2012. Disponível em: https://bvsms.saude.gov.br/bvs/saudelegis/gm/2011/prt2914_12_12_2011.html. Acesso em: 20/02/2021.

Brasil. (2013). Ministério da Saúde. Secretaria de Vigilância em Saúde. Departamento de Vigilância em Saúde Ambiental e Saúde do Trabalhador. Análise de indicadores relacionados à água para consumo humano e doenças de veiculação hídrica no Brasil, utilizando a metodologia da matriz de indicadores da Organização Mundial da Saúde / Ministério da Saúde,

Brasil. (2020a). Ministério do Desenvolvimento Regional. Secretaria Nacional de Saneamento - SNS. Sistema Nacional de Informações sobre Saneamento: $25^{\circ}$ Diagnóstico dos Serviços de Água e Esgotos - 2019. Brasília: SNS/MDR, 183 p.: il.

Brasil. (2020b). Ministério do Desenvolvimento Regional. Secretaria Nacional de Saneamento - SNS. Sistema Nacional de Informações sobre Saneamento: Diagnóstico do Manejo de Resíduos Sólidos Urbanos - 2019. Brasília: SNS/MDR, 244 p.: il.

Brasil. [Constituição (1988)]. Constituição da República Federativa do Brasil. Brasília, DF: Presidência da República, 1988. Disponível em: http://www.planalto.gov.br/ccivil_03/constituicao/constituicao.htm. Acesso em: 28 mar. 2020.

Brasil. (1971). Lei No 6.307, de 29 de julho de 1971. Disponível em: https://legis.alepe.pe.gov.br/texto.aspx?id=1047\&tipo=. Acesso em: 20/10/2021.

Brito, A. L. (2020). As tarifas sociais de abastecimento de água e esgotamento sanitário no Brasil: seus impactos nas metas de universalização na garantia dos direitos humanos à água e ao esgotamento sanitário. Observatório Nacional dos Direitos à Água e ao Saneamento - ONDAS. https://ondasbrasil.org/wpcontent/uploads/2020/05/As-tarifas-sociais-de-abastecimento-de-\%C3\%A1gua-eesgotamento-sanit\%C3\%A1 rio-no-Brasil.pdf. Acesso em: 20/10/2021.

Cairncross, S. \& Valdmanis, V. (2006) Water Supply, Sanitation, and Hygiene Promotion. In: Jamison, D.T.; Breman, J.G. \& Measham, A.R. Disease Control Priorities in Developing Countries. 2. ed. Washington, D.C.: The International Bank for Reconstruction and Development / The World Bank

Carcará, M. S. M.; Silva, E. A. \& Neto, J. M. M. (2019). Saneamento básico como dignidade humana: entre o mínimo existencial e a reserva do possível. Eng Sanit Ambient, v. 24 n.3, maio/jun.

Castro, L.A; Taleires, F.C.S.S. \& Silveira, S.S. (2019). Índice de desenvolvimento humano em municípios que possuem sistema integrado de saneamento rural: Uma análise comparativa. Cien Saude Colet, jun. Disponível em: http://www.cienciaesaudecoletiva.com.br/artigos/indice-de-desenvolvimento-humanoem-municipios-que-possuem-sistema-integrado-de-saneamento-rural-uma-analise-comparativa/17245?id=17245 Acesso em: 20/02/2021.

Corrêa, F.V. \& Palhares, J.M. (2016). Aumento de casos de dengue relacionados com fatores climáticos e o meio socioambiental no município de OiapoqueAP - Brasil: período de 2008 a 2013. Ciência Geográfica, 20(1), p. 58-70.

DATASUS. (2016). Departamento de Informática do SUS. Disponível em: http://datasus1.saude.gov.br/transferencia-download-de-arquivos/download-dotabwin Acesso em: 20/02/2021.

Diário Oficial da União. (2020). Lei no 14.026, de 15 de julho de 2020. Atualiza o marco legal do saneamento básico e altera a Lei ${ }^{\circ} 9.984$, de 17 de julho de 2000. Disponível em: https://www.in.gov.br/web/dou/-/lei-n-14.026-de-15-de-julho-de-2020-267035421 Acesso em: 20/02/2021.

Dias, D. M.; Silva, A.P.; Helfer, A.M.; Maciel, A.M.T.R.; Loureiro, E.C.B. \& Souza, C.O. (2010). Morbimortalidade por gastroenterites no Estado do Pará. Rev. Pan-Amaz. Saude, Ananindeua, v. 1, n. 1, p. 53-60, mar. Disponível em: http://scielo.iec.pa.gov.br/scielo.php?script=sci_arttext\&id=S217662232010000100008\&lng =pt\&nrm=iso Acesso em: 20/02/2021.

Feachem, R. G.; Bradley, D. J. \& Garelick H, \& Mara, D. D. Chichester (1983). Sanitation and disease. Health aspects of waste water and excreta management. Chichester: John Wiley \& Sons.

Felippe, C. Y. (2020). Direito humano à água: uma análise sob a luz do recente marco legal do saneamento básico, 20 f, Trabalho de Conclusão de Curso (graduação em direito) - UniCesumar, Maringá.

Gadelha, S. H., Marques, T. A., Neto, B. C. F., Lima, A. F. M., Almeida, S. R., Neto, M. J., Soares, F. J., Nóbrega, S. C. J., Oliveira, S. D. J., Maracajá, B. P. (2021). O novo marco regulatório do saneamento básico e o direito ao acesso à água. Research, Society and Development, v. 10, n. 11.

IBGE. Pesquisa de Informações Básicas Municipais - MUNIC. (2018). Disponível em: https://www.ibge.gov.br/estatisticas/sociais/educacao/10586-pesquisade-informacoes-basicas-municipais.html?=\&t=destaques Acesso em: 20/02/2021.

IBGE. Pesquisa Nacional de Saneamento Básico. (2017). Disponível em: https://www.ibge.gov.br/estatisticas/multidominio/meio-ambiente/9073-pesquisanacional-de-saneamento-basico.html?=\&t=o-que-e Acesso em: 20/02/2021.

Instituto Trata Brasil. (2020). Cartilha Recomendações para prevenção do contágio da COVID-19 (Novo Coronavírus - SARS-CoV-2) pela água e por esgoto doméstico, p. 17. Disponível em: http://tratabrasil.org.br/covid-19/assets/pdf/cartilha_covid-19.pdf Acesso em: 20/02/2021.

Instituto Trata Brasil. (2021). Ranking do Saneamento 2021. Sistema Nacional de Informações sobre Saneamento (SNIS), p. 106 e 110. Disponível em: http://www.tratabrasil.org.br/images/estudos/Ranking_saneamento_2021/Relat\%C3\%B3rio_-_Ranking_Trata_Brasil_2021_v2.pdf Acesso em: 20/02/2021.

Landau, E.C. \& Moura, L. (2016). Variação geográfica do saneamento básico no Brasil em 2010: domicílios urbanos e rurais. Brasília, DF: Embrapa.

Lima-Camara, T.N. Arboviroses emergentes e novos desafios para a saúde pública no Brasil. Revista de Saúde Pública, p. 50-36, 2016. Disponível em: https://doi.org/10.1590/S1518-8787.2016050006791 Acesso em: 20/02/2021.

Maia, B. L. I. (2017). O acesso a água potável como direito humano fundamental no direito brasileiro. Revista do CEPEJ, Salvador, vol. 20. file://C:/Users/santo/Downloads/27165-94706-1-PB.pdf. Acesso em: 12/10/2021. 
Mol, M.P.G.; Queiroz, J.T.M.; Gomes, J. \& Heller, L. (2020). Gestão adequada de resíduos sólidos como fator de proteção na ocorrência da dengue. Rev Panam Salud Publica, 44, e 22. Disponível em: https://doi.org/10.26633/RPSP.2020.22 Acesso em: 20/02/2021.

Moraes, D.S.L. \& Jordão, B.Q. (2002). Degradação de recursos hídricos e seus efeitos sobre a saúde humana. Revista Saúde Pública, v. 36, n. 3, p. 370-374.

Neri, M.C. (2008). Trata Brasil: Saneamento e Saúde, 2007. Rio de Janeiro: FGV; IBRE.

OMS. (2017a). World Health Organization. Guidelines for drinking-water quality: fourth edition incorporating the first addendum, Geneva. Disponível em: https://www.who.int/publications/i/item/9789241549950 Acesso em: 20/02/2021.

OMS. (2017b). Relatório UM. Water Global Analysis and Assessment of Sanitation and Drinking-Water (GLAAS). Disponível em: https://www.unwater.org/publication_categories/glaas/ Acesso em: 20/02/2021.

OMS. (2018). Guidelines on sanitation and health. Geneva: World Health Organization. Licence: CC BY-NC-SA 3.0 IGO. Disponível em: https://apps.who.int/iris/bitstream/handle/10665/274939/9789241514705-eng.pdf?ua=1 Acesso em: 20/02/2021.

OMS. (2019). Water, sanitation, hygiene and health: a primer for health professionals. Geneva: World Health Organization.

OMS. (2020a). World health statistics: monitoring health for the SDGs, sustainable development goals. Geneva: World Health Organization. Disponível em: https://apps.who.int/iris/bitstream/handle/10665/332070/9789240005105-eng.pdf Acesso em: 20/02/2021.

OMS. (2020b). Technical brief on water, sanitation, hygiene and wastewater management to prevent infections and reduce the spread of antimicrobial resistance. World Health Organization (WHO), Food and Agriculture Organization of the United Nations (FAO) and World Organisation for Animal Health (OIE). Disponível em: https:/www.who.int/water_sanitation_health/publications/wash-wastewater-management-to-prevent-infections-and-reduce-amr/en/ Acesso em: 20/02/2021.

OMS. (2020c). Water, sanitation, hygiene, and waste management for SARS-CoV-2, the virus that causes COVID-19: Interim guidance. WHO and UNICEF. Disponível em: https://www.who.int/publications-detail/water-sanitation-hygiene-and-waste-management-for-covid-19 Acesso em: $20 / 02 / 2021$.

ONU - Organização das Nações Unidas. (2017). Roteiro para a localização dos objetivos de desenvolvimento sustentável: implementação e acompanhamento no nível subnacional. Brasília, DF: ONU, 2017. Disponível em: https://www.br.undp.org/content/dam/brazil/docs/ODS/ undp-br-roteiro-localizacao-objetivosdesenvolvimento-2017.pdf. Acesso em: 21/10/2021.

Pereira JR, J. S. (2008). Aplicabilidade da Lei $n^{\circ}$ 11.445/2007. Diretrizes Nacionais para o Saneamento Básico; Estudo Técnico. Consultoria Legislativa, Câmara dos Deputados, 2008. Disponível em: http://www.daaerioclaro.sp.gov.br/arquivos/regulacao/04-A-aplicacao-da-Leide-Saneamento-2.pdf. Acesso em: $21 / 10 / 2021$

Razzolini, M.T.P. \& Günther, W.M.R. (2008). Impactos na saúde das deficiências de acesso a água. Saúde Soc., 17(1), p. 21-32.

Rodrigues, A.S.L. \& Malafaia, G. (2009). Degradação dos recursos hídricos e saúde humana: uma atualização. Revista Saúde e Ambiente, v. 10, n. 1, p. 13-23.

Rother, E.T. (2007). Revisão sistemática X revisão narrativa. Acta paul. Enferm, 20 (2), p. v-vi.

Santiago, C.; Pugliesi, E.; Massukado, L. \& Kotaka, F. (2020). Contribuições da Fundação Nacional de Saúde na pesquisa em saúde e saneamento no Brasil. Saude soc. v. 29, n.2, São Paulo, Epub May, 18.

São Paulo. (2009). Divisão de Doenças de Transmissão Hídrica e Alimentar (DDTHA). Doenças relacionadas à Água ou de Transmissão Hídrica (Informe Técnico). Centro de Vigilância Epidemiológica (CVE), CCD/SES-SP., 25 p.

Scott, R.; Cotton, A.P. \& Govindan, B. (2003). Sanitation and the Poor. Loughborough, Londres e Delft: WELL Resource Centre.

Silva, R.C.P.; Costa, A.R.S.; El-Deir, S.G. \& Jucá, J.F.T. (2020). Setorização de rotas de coleta de resíduos sólidos domiciliares por técnicas multivariadas: estudo de caso da cidade do Recife, Eng Sanit Ambient, v. 25, n. 6, nov/dez, p. 821-832.

Silva, S. A.; Gama, J. A. S.; Callado, N. H. \& Souza, V. C. B. (2017). Saneamento básico e saúde pública. na Bacia Hidrográfica do Riacho Reginaldo em Maceió, Alagoas. Eng Sanit Ambient, v. 22, n. 4, jul/ago, 699-709.

SNIS. (2020). Disponível em: http://app4.mdr.gov.br/serieHistorica/. Acesso em: 20/02/2021.

United Nations. (2010). Word General Assembly Resolution 64/292: The Human Right to Water and Sanitation. http://www.un.org/es/comun/docs/?symbol=A/RES/64/292\&lang=E. Acesso em: 12/10/2021.

Vila Nova, F.V.P. \& Tenório, N.B. (2019). Doenças de Veiculação Hídrica Associadas à Degradação dos Recursos Hídricos, Município de Caruaru - PE. Caminhos de Geografia Uberlândia-MG v. 20, n. 71, setembro, p. 250-264. 